\title{
Association of Intraoperative Hypotension with Acute Kidney Injury after Noncardiac Surgery in Patients Younger than 60 Years Old
}

\author{
Yongzhong Tang ${ }^{\mathrm{a}}$ Chaonan Zhu ${ }^{\mathrm{b}}$ Jiabin Liu ${ }^{\mathrm{c}}$ Anli Wang ${ }^{\mathrm{d}}$ Kaiming Duan ${ }^{\mathrm{a}}$ \\ Bo Lie Hong Yuan ${ }^{f}$ Hao Zhang ${ }^{g}$ Min Yao $^{h}$ Wen Ouyang ${ }^{a}$ \\ ${ }^{a}$ Center of Anesthesiology, The Third Xiangya Hospital, Central South University, Changsha, \\ PR China; ${ }^{\text {b School of Medicine, Zhejiang University, Hangzhou, PR China; ' } D e p a r t m e n t ~ o f ~}$ \\ Anesthesiology, Hospital for Special Surgery, New York, NY, USA; ${ }^{2}$ Information Department, \\ The Third Xiangya Hospital, Central South University, Changsha, PR China; ${ }^{e}$ Operation \\ Room, The Third Xiangya Hospital, Central South University, Changsha, PR China; \\ fDepartment of Clinical Pharmacology, The Third Xiangya Hospital, Central South University, \\ Changsha, PR China; ${ }^{9}$ Institute of Microelectronics of Chinese of Science, Beijing, PR China; \\ hDepartment of Surgery, Boston Medical Center and Boston University School of Medicine, \\ Boston, MA, USA
}

\section{Keywords}

Acute kidney injury · Intraoperative hypotension · Noncardiac surgery

\begin{abstract}
Background/Aims: Intraoperative hypotension $(\mathrm{IOH})$ may be associated with surgery-related acute kidney injury (AKI). However, the duration of hypotension that triggers AKI is poorly understood. The incidence of AKI with various durations of $\mathrm{IOH}$ and mean arterial pressures (MAPs) was investigated. Materials: A retrospective cohort study of 4,952 patients undergoing noncardiac surgery (2011 to 2016) with MAP monitoring and a length of stay of one or more days was performed. The exclusion criteria were a preoperative estimated glomerular filtration (eGFR) $\leq 60 \mathrm{~mL} \mathrm{~min}{ }^{-1} 1.73 \mathrm{~m}^{2-1}$, a preoperative MAP less than $65 \mathrm{~mm} \mathrm{Hg}$, dialysis dependence, urologic surgery, age older than 60 years, and a surgical duration of less than 60 min. The primary exposure was $\mathrm{IOH}$, and the primary outcome was AKI ( $50 \%$ or $0.3 \mathrm{mg} \mathrm{dL}^{-1}$ increase in creatinine) during the first 7 postoperative days. Multivariable logistic regression was used to model the exposure-outcome relationship. Results: AKI occurred in 186 (3.76\%) noncardiac surgery patients. The adjusted odds ratio for surgery-related AKI for a MAP of less than $55 \mathrm{~mm} \mathrm{Hg}$ was 14.11 (95\% confidence interval: 5.02-39.69) for an exposure of more than
\end{abstract}




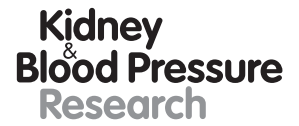

Research

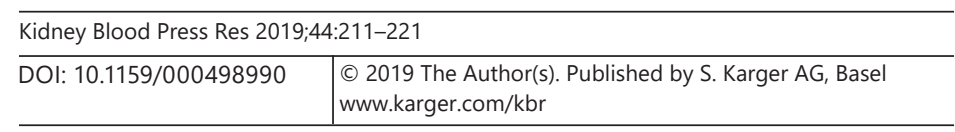

Tang et al.: Noncardiac Surgery-Related Acute Kidney Injury after Intraoperative Hypotension

20 min. Age was not an interaction factor between AKI and IOH. Conclusion: There was a considerably increased risk of postoperative AKI when intraoperative MAP was less than 55 $\mathrm{mm} \mathrm{Hg}$ for more than $10 \mathrm{~min}$. Strict blood pressure management is recommended even for patients younger than 60 years old.

(c) 2019 The Author(s)

Published by S. Karger AG, Basel

\section{Background}

The incidence of surgery-related acute kidney injury (AKI) has been reported to be as high as $21.6 \%$ in adults [1] and $18.3 \%$ in hospitalized individuals [2]. Surgery-related AKI is a serious complication that is associated not only with short-term increases in mortality [3] but also with long-term complications [4], such as the development of chronic kidney disease. Surgical patients who develop AKI are eight times more likely to die within 30 days of surgery [5]. A recent meta-analysis demonstrated that hospitalized medical patients with an increase of more than 50\% in their baseline creatinine (Acute Kidney Injury Network [AKIN] [6] stage I) were 6.9 times more likely to die (95\% confidence interval [CI], 2.0 to 24.5) [7].

Perioperative hypotension is fairly common [8] and is defined as less than $90 \mathrm{~mm} \mathrm{Hg}$ systolic blood pressure (BP). It is an important risk factor for postoperative AKI and other postoperative complications [4]. In a large retrospective analysis, Walsh et al. [9] found that noncardiac patients were at risk of developing AKI if they had a mean arterial pressure (MAP) of 55 to $59 \mathrm{~mm} \mathrm{Hg}$ lasting for more than $5 \mathrm{~min}$. However, this study included patients with baseline MAP values less than the tested thresholds, did not establish a clear algorithm for stratifying BP measurements, and used an expanded AKIN definition of AKI. The observed increases in serum creatinine 7 days after surgery were therefore likely due to confounding postoperative events that were independent of intraoperative hypotension (IOH).

Sun et al. [10] performed another large retrospective analysis regarding the duration of $\mathrm{IOH}$ and its effect on AKI. When the intraoperative MAP was less than $60 \mathrm{~mm} \mathrm{Hg}$ for more than 20 min or less than $55 \mathrm{~mm} \mathrm{Hg}$ for more than 10 min there was an increased risk of postoperative AKI (defined as a more than $50 \%$ or $0.3 \mathrm{mg} \mathrm{dL}^{-1}$ increase in serum creatinine concentration).

However, in a retrospective study involving 57,315 patients, Vafi Salmasi et al. [11] suggested that the relationship between IOH and AKI based on absolute thresholds was stronger than that based on relative thresholds.

The positive correlation between IOH and surgery-related AKI seem to have been established by these previous studies. However, whether the same correlation exists between IOH and AKI in patients younger than 60 years old has not been widely studied. Thus, we conducted a single-centre retrospective cohort study to determine whether the IOH was less strongly positive related to surgery-related AKI or not in patients younger than 60 years old.

\section{Materials and Methods}

\section{Study Design and Cohort Selection}

The Third Xiangya Hospital is a 1,500-bed tertiary care major academic medical centre. This study was approved by the institutional review board (IRB No. 2017-S213). The enrolment criteria included a length of stay of at least 1 day, serum creatinine test performed in-hospital, age between 18 and 60 years old, and noncardiac surgery performed between Dec. 1, 2011, and July 1, 2016.

The exclusion criteria were a baseline MAP less than $65 \mathrm{~mm} \mathrm{Hg}$, preoperative dialysis dependence, urologic surgery, and an estimated glomerular filtration (eGFR) $\leq 60 \mathrm{~mL} \mathrm{~min}^{-1}$ 


\section{Kidney \\ Blood Pressure \\ Research}

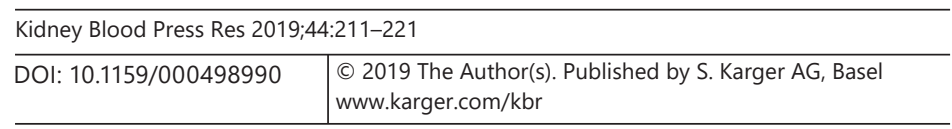

Tang et al.: Noncardiac Surgery-Related Acute Kidney Injury after Intraoperative Hypotension

$1.73 \mathrm{~m}^{2-1}$. Patients who underwent urologic procedures were excluded because associated changes in postoperative creatinine may be more directly related to the surgical intervention (e.g., nephrectomy) in these patients.

\section{Intraoperative Blood Pressure}

MAP and Artefact Removing Algorithm. The intraoperative MAP was extracted directly from our electronic medical record. It cannot be modified by clinicians but can be identified as artefactual. Invasive BPs were recorded at 30 seconds intervals; non-invasive BPs were recorded at 3- to 5-min intervals. We removed artefacts using the following rules, in order: (1) BPs documented as artefacts; (2) BPs out-of-range as defined by (a) SBP $\geq 300 \mathrm{~mm} \mathrm{Hg}$ or SBP $\leq 20 \mathrm{~mm} \mathrm{Hg}$, (b) SBP $\leq \mathrm{DBP}+5 \mathrm{~mm} \mathrm{Hg}$, or (c) DBP $\leq 5 \mathrm{~mm} \mathrm{Hg}$ or DBP $\geq 225 \mathrm{~mm} \mathrm{Hg}$, and (d) MAP $\leq 25 \mathrm{~mm} \mathrm{Hg}$; and (3) abrupt changes in SBP $\geq 80 \mathrm{~mm} \mathrm{Hg}$ within 1 min in either direction or abrupt changes in SBP $\geq 40 \mathrm{~mm}$ Hg within $2 \mathrm{~min}$ in both directions. BPs between measurements were linearly interpolated. Anaesthesia time was defined as the interval between induction and recovery. The MAP was recorded every $30 \mathrm{~s}$ when an arterial catheter was used (4,377/4,952, 88.4\% of patients). If an arterial catheter line was not used, noninvasive BP monitoring was performed instead. The MAP was recorded every 5 min when non-invasive BP monitoring was used, which also was extracted from the electronic medical records. In case in which no BP was recorded over $5 \mathrm{~min}$ or when a reading was marked as an artefact by the attending anaesthesiologist, we ignored these MAPs and the last non-artefactual BP was used for calculation purposes.

For each patient, we first calculated the total number of minutes with a MAP $<55,55-59$, 60-64, 65-69, and 70-74 mm Hg. Then, we also calculated the number of patients in these 6 MAP groups. Eventually, we focused our analysis on 3 groups (MAP $<55,55-59$, and 60-64 $\mathrm{mm} \mathrm{Hg).}$

\section{Data Sources}

Our data including baseline data, comorbidities, perioperative data, and other medical data was collected from electronic medical records with Lex Clinical Research Data Warehouse Software (Le9 Healthcare Technology, Shanghai, China), which includes an intuitive data access tool designed to query clinical data warehouses and return tabular data for analysis and visualization. In addition, we also checked the data that was collected by this software again to make sure the research data was complete and correct.

\section{Outcomes and Exposures}

The primary outcome was AKI as defined by the Kidney Disease: Improving Global Outcomes (KDIGO) [12] criteria $\left(0.3 \mathrm{mg} \mathrm{dL}^{-1}\right.$ increase in creatinine greater than the preoperative value during the first two postoperative days or more than a 1.5 -fold increase from the baseline). Using intraoperative BP measurements in the EMR-Lite database, the primary exposure, namely, $\mathrm{IOH}$, was defined as a MAP below one of three a priori designated thresholds (MAP <55, 55-59, and 60-64 $\mathrm{mm} \mathrm{Hg}$ ).

\section{Statistical Analysis}

Bivariate analyses were used to compare the characteristics of patients with and without $\mathrm{IOH}$ for each of the specified hypotension thresholds. Continuous variables were analysed using ANOVA and presented as the mean and standard deviation (SD). Categorical variables were analysed using the chi-square test and reported as numbers and proportions.

We first assessed the relationship between the total amount of time spent under each MAP threshold $(<55,55-59,60-64,65-69$, and 70-74 $\mathrm{mm} \mathrm{Hg}$ ) and each outcome using restricted cubic splines in a logistic regression model. For each threshold, the odds ratios 


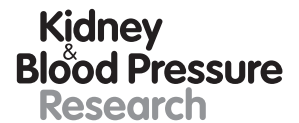

Kidney
Blood Pressure
Research

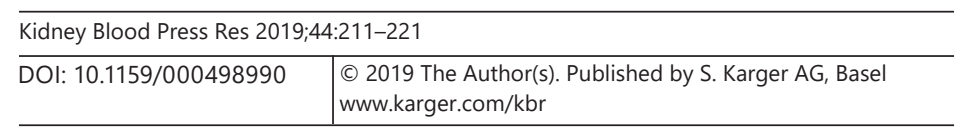

Tang et al.: Noncardiac Surgery-Related Acute Kidney Injury after Intraoperative Hypotension

appeared to increase rapidly initially for each minute spent under the threshold for approximately $10 \mathrm{~min}$, followed by a steadier increase thereafter. Therefore, we categorized patients as having sustained $0,1-5,6-10,11-20$, or more than $20 \mathrm{~min}$ in each strata and restricted MAPs to below one of the three a priori designated thresholds (MAP $<55,55-59$, and 60-64 $\mathrm{mm} \mathrm{Hg}$ ).

The adjusted relationship between $\mathrm{IOH}$ and AKI was then modelled using multivariable logistic regression with adjustment for a priori selected risk factors for AKI. These risk factors included age, sex, hypertension, coronary heart disease, peripheral vascular disease, haemoglobin, duration of surgery, magnitude of surgery, general anaesthesia, blood loss, medication use (ACE inhibitors, $\beta$-blockers, calcium antagonists and diuretics), eGFR, intensive care unit (ICU) stay, and American Society of Anesthesiologists (ASA) grade [13]. We reported adjusted odds ratios and associated $95 \%$ CIs and $p$ values.

All statistical analyses were performed using SAS version 9.4 software (SAS Institute, Inc., Cary, NC, USA) and CRAN R (v3.4.1). All statistical tests were two-tailed, and $p<0.05$ was considered significant.

\section{Results}

Of the 4,952 included patients, 186 (3.76\%) developed AKI. Table 1 compared the characteristics of patients with and without AKI. Single-variable logistic regression analysis showed that the magnitude and duration of $\mathrm{IOH}$ were significant risk factors for AKI, and there was a positive correlation between the risk of AKI and the magnitude and duration of IOH (Fig 1). Table 2 showed the proportion of patients experiencing AKI, which was stratified by hypotension duration for MAP thresholds of 55, 60, and $65 \mathrm{~mm} \mathrm{Hg}$. Figure 2 predicted the probability of AKI by lowest mean arterial pressure experienced during surgery. After adjustment for age, sex, hypertension, coronary heart disease, peripheral vascular disease, haemoglobin, duration of surgery, magnitude of surgery, anaesthesia method, blood loss, medication use (ACE inhibitors, calcium antagonists, $\beta$-blockers, and diuretics), and ASA grade, we found that a duration of $\mathrm{IOH}$ more than $20 \mathrm{~min}$ was a significant risk factor for AKI (Table 3).

As shown in Table 4, we constructed model 1 with age and sex as the dependent variables and conducted a multivariate analysis. Next, after the collinear analysis was performed, haemoglobin, ASA grade, use of ACE inhibitors, $\beta$-blockers, $\alpha$-blockers, or diuretics, minimally invasive surgery, magnitude of surgery, emergency surgery, anaesthesia time, intraoperative erythrocyte transfusion, intraoperative haemorrhage, duration of surgery were then integrated into regression model 2 . In regression model 3 , the clinical risk factors, hypertension, coronary heart disease, congestive heart failure, peripheral vascular disease, diabetes, and general anaesthesia were included as independent variables. These analyses indicated that a BP of less than $55 \mathrm{~mm} \mathrm{Hg}$ for longer than $10 \mathrm{~min}$ was a serious risk factor for AKI.

AKI was categorized as three AKI stages by KDIGO. We then constructed multinomial logistic regression model with different AKI stages as the dependent variable, IOH as independent variable, and adjusted all the risk factors. The result showed that MAP less than 55 $\mathrm{mm} \mathrm{Hg}$ for more than $10 \mathrm{~min}$ was a serious factor of AKI stage I, and IOH was longer than 20 minutes was a serious factor of AKI stage II and stage III (Table 5).

These finding suggests that hypotension and the duration of hypotension may play a considerable role in the development of AKI.

To explore whether the age was an interaction factor (Table 6), model 1 did not have any adjustments, model 2 was adjusted for age, and model 3 was adjusted for age and the inter- 
Table 1. Baseline and intraoperative characteristics of patients

\begin{tabular}{|c|c|c|c|c|c|c|}
\hline Factors & $\begin{array}{l}\text { MINS } \\
(n=2,073)\end{array}$ & $\begin{array}{l}\text { Non-MINS } \\
(n=2,879)\end{array}$ & $\begin{array}{l}p \\
\text { value }\end{array}$ & $\begin{array}{l}\text { AKI } \\
(n=186)\end{array}$ & $\begin{array}{l}\text { Non-AKI } \\
(n=4,766)\end{array}$ & $\begin{array}{l}p \\
\text { value }\end{array}$ \\
\hline \multicolumn{7}{|l|}{ Baseline } \\
\hline Age $^{1}$, years & $46.12 \pm 9.46$ & $44.13 \pm 10.28$ & $<0.001$ & $44.13 \pm 9.53$ & $44.99 \pm 10.01$ & 0.250 \\
\hline Female, $n(\%)$ & $921(44.43)$ & $1,556(54.05)$ & $<0.001$ & $75(40.32)$ & $2,402(50.4)$ & 0.007 \\
\hline Hypertension, $n(\%)$ & 715 (34.49) & $1,099(38.17)$ & 0.008 & $68(36.56)$ & $1,746(36.63)$ & 0.983 \\
\hline Coronary heart disease, $n(\%)$ & $101(4.87)$ & $107(3.72)$ & 0.046 & $8(4.3)$ & $200(4.2)$ & 0.944 \\
\hline Congestive heart failure, $n(\%)$ & $1(0.05)$ & $1(0.03)$ & 0.816 & $0(0)$ & $2(0.04)$ & 0.780 \\
\hline PVD, $n(\%)$ & $147(7.09)$ & $258(8.96)$ & 0.018 & $13(6.99)$ & $392(8.22)$ & 0.546 \\
\hline Diabetes, $n(\%)$ & $289(13.94)$ & $470(16.33)$ & 0.022 & $31(16.67)$ & $728(15.27)$ & 0.605 \\
\hline eGFR, $\mathrm{mL} / \mathrm{min}$ & $108.4 \pm 16.3$ & $109.2 \pm 15.91$ & 0.062 & $111.8 \pm 22.8$ & $108.7 \pm 15.75$ & 0.071 \\
\hline Haemoglobin $^{1}, \mathrm{~g} / \mathrm{L}$ & $123.2 \pm 24.09$ & $126.5 \pm 21.73$ & $<0.001$ & $117.9 \pm 27.69$ & $125.4 \pm 22.56$ & $<0.001$ \\
\hline \multicolumn{7}{|l|}{ ASA grade, $n(\%)$} \\
\hline I & 77 (3.72) & 407 (14.17) & $<0.001$ & $10(5.38)$ & $474(9.96)$ & $<0.001$ \\
\hline II & $1,299(62.69)$ & $2,051(71.41)$ & & $68(36.56)$ & $3,282(68.98)$ & \\
\hline III & $586(28.28)$ & $361(12.57)$ & & $64(34.41)$ & $883(18.56)$ & \\
\hline IV & $100(4.83)$ & $49(1.71)$ & & $40(21.51)$ & $109(2.29)$ & \\
\hline $\mathrm{V}$ & $10(0.48)$ & $4(0.14)$ & & $4(2.15)$ & $10(0.21)$ & \\
\hline \multicolumn{7}{|l|}{ Preoperative medications } \\
\hline ACE inhibitors & $61(3.03 \%)$ & 35 (1.24\%) & $<0.001$ & $5(5.75 \%)$ & $91(1.91 \%)$ & 0.011 \\
\hline ARB & $19(0.95 \%)$ & $36(1.27 \%)$ & 0.291 & $2(2.3 \%)$ & $53(1.11 \%)$ & 0.302 \\
\hline$\beta$-Blockers & 87 (4.33\%) & $71(2.51 \%)$ & $<0.001$ & $21(24.14 \%)$ & $137(2.88 \%)$ & $<0.001$ \\
\hline$\alpha$-Blockers & $6(0.3 \%)$ & $9(0.32 \%)$ & 0.905 & $3(3.45 \%)$ & $12(0.25 \%)$ & $<0.001$ \\
\hline Antihypertensives & $13(0.65 \%)$ & $12(0.42 \%)$ & 0.286 & $1(1.15 \%)$ & $24(0.5 \%)$ & 0.406 \\
\hline Calcium antagonists & $298(14.83 \%)$ & $307(10.84 \%)$ & $<0.001$ & $16(18.39 \%)$ & $589(12.39 \%)$ & 0.094 \\
\hline Diuretics & $27(1.34 \%)$ & $19(0.67 \%)$ & 0.018 & $4(4.6 \%)$ & $42(0.88 \%)$ & $<0.001$ \\
\hline \multicolumn{7}{|l|}{ Surgery-related factors } \\
\hline Minimally invasive surgery, $n(\%)$ & $1,196(25.09)$ & $21(11.29)$ & $<0.001$ & $21(11.29)$ & $1,196(25.09)$ & $<0.001$ \\
\hline \multicolumn{7}{|l|}{ Magnitude of surgery, $n(\%)$} \\
\hline 1 & $6(0.29)$ & $78(2.71)$ & $<0.001$ & $2(1.08)$ & $82(1.72)$ & 0.004 \\
\hline 2 & $415(20.11)$ & $1,458(50.71)$ & & $52(28.11)$ & $1,821(38.3)$ & \\
\hline 3 & $1,555(75.34)$ & $1,284(44.66)$ & & $120(64.86)$ & $2,719(57.19)$ & \\
\hline 4 & $88(4.26 \%)$ & $55(1.91)$ & & $11(5.95)$ & $132(2.78)$ & \\
\hline Emergency surgery, $n(\%)$ & 393 (19.29) & $445(15.83)$ & 0.002 & $88(49.16)$ & $750(16.06)$ & $<0.001$ \\
\hline General anaesthesia, $n(\%)$ & $2,033(98.07)$ & $2,524(87.67)$ & $<0.001$ & $175(94.09)$ & $4,382(91.94)$ & 0.290 \\
\hline Anaesthesia time $\mathrm{e}^{1} \mathrm{~h}$ & $4.92 \pm 2.1$ & $3.34 \pm 1.5$ & $<0.001$ & $4.8 \pm 2.63$ & $3.97 \pm 1.9$ & $<0.001$ \\
\hline \multicolumn{7}{|c|}{ Intraoperative erythrocyte transfusions, $\mathrm{mL}(\%)$} \\
\hline$\leq 100$ & $1,303(62.86)$ & $2,510(87.18)$ & $<0.001$ & $91(48.92)$ & $3,722(78.09)$ & $<0.0001$ \\
\hline $101-600$ & $329(15.87)$ & $203(7.05)$ & & $31(16.67)$ & $501(10.51)$ & \\
\hline$>600$ & $172(8.3)$ & 97 (3.37) & & $16(8.6)$ & $253(5.31)$ & \\
\hline$>1,000$ & $269(12.98)$ & $69(2.4)$ & & $48(25.81)$ & $290(6.08)$ & \\
\hline \multicolumn{7}{|l|}{ Intraoperative hemorrhage, $\mathrm{mL}(\%)$} \\
\hline$\leq 100$ & $403(19.44)$ & $1,642(57.03)$ & $<0.001$ & $51(27.42)$ & $1,994(41.84)$ & $<0.0001$ \\
\hline $101-600$ & $1,106(53.35)$ & $1,006(34.94)$ & & $72(38.71)$ & $2,040(42.8)$ & \\
\hline $601-1,000$ & 268 (12.93) & $144(5)$ & & $19(10.22)$ & $393(8.25)$ & \\
\hline$>1,000$ & $296(14.28)$ & $87(3.02)$ & & $44(23.66)$ & $339(7.11)$ & \\
\hline \multicolumn{7}{|l|}{ Duration of surgery, h (\%) } \\
\hline$\leq 2$ & 265 (12.78) & $1,225(42.55)$ & $<0.001$ & 47 (25.27) & $1,443(30.28)$ & $<0.001$ \\
\hline $2-5$ & $1,389(67)$ & $1,512(52.52)$ & & $96(51.61)$ & $2,805(58.85)$ & \\
\hline$\geq 5$ & 419 (20.21) & $142(4.93)$ & & $43(23.12)$ & $518(10.87)$ & \\
\hline In fluids amount ${ }^{2}, 10 \mathrm{~mL} / 24 \mathrm{~h}$ & $312(250-400)$ & $200(150-300)$ & $<0.001$ & $279(200-390)$ & $250(160-350)$ & 0.001 \\
\hline Out fluids amount ${ }^{2}, 10 \mathrm{~mL} / 24 \mathrm{~h}$ & $80(50-125)$ & $50(25-80)$ & $<0.001$ & $80(50-130)$ & $60(30-100)$ & $<0.001$ \\
\hline
\end{tabular}

${ }^{1}$ Mean \pm SD. ${ }^{2}$ Median $\left(\mathrm{P}^{25}-\mathrm{P}^{75}\right)$. ASA, American Society of Anaesthesiologists; eGFR, estimated glomerular filtration rate; MAP, mean arterial pressure; AKI, acute kidney injury; PVD, peripheral vascular disease; ARB, angiotensin receptor blockers. 
Tang et al.: Noncardiac Surgery-Related Acute Kidney Injury after Intraoperative

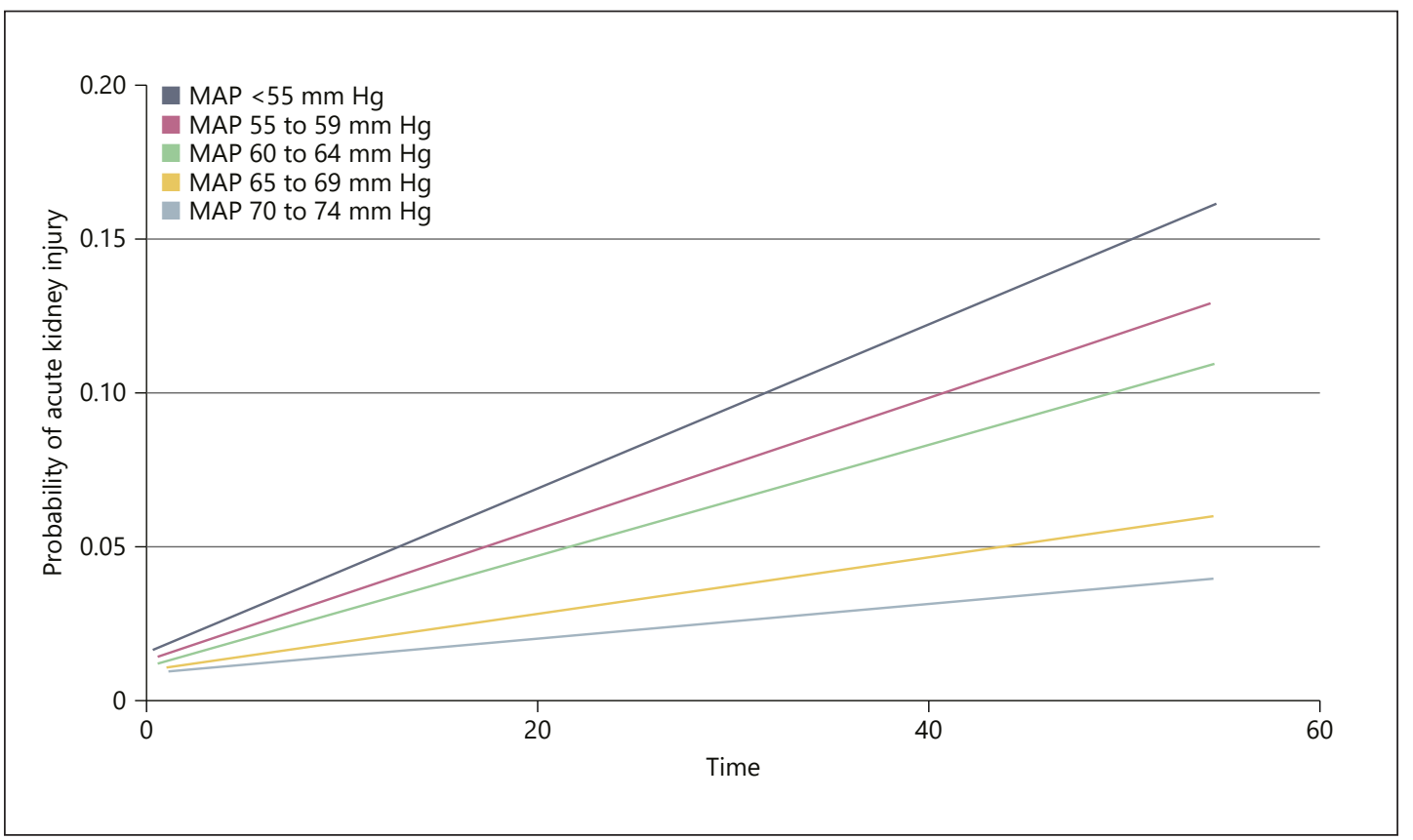

Fig. 1. Predicted risk of acute kidney injury for each minute the mean arterial pressure (MAP) is $<55,55-59$, 60-64, 65-69, and 70-74 mm Hg during noncardiac surgery.

Table 2. Proportion of patients experiencing AKI, stratified by hypotension duration for MAP thresholds of 55,60 , and $65 \mathrm{~mm} \mathrm{Hg}$

\begin{tabular}{lrlllll}
\hline \multirow{2}{*}{ IOH duration, min } & \multicolumn{2}{c}{$\mathrm{MAP}<55 \mathrm{~mm} \mathrm{Hg}$} & \multicolumn{2}{c}{$\mathrm{MAP}<60 \mathrm{~mm} \mathrm{Hg}$} & \multicolumn{2}{c}{$\mathrm{MAP}<65 \mathrm{~mm} \mathrm{Hg}$} \\
& $n$ & AKI & $n$ & AKI & $n$ & AKI \\
\hline 0 & 2,879 & $71(2.47)$ & 2,580 & $59(2.29)$ & 2,186 & $49(2.24)$ \\
$1-5$ & 1,723 & $77(4.47)$ & 1,760 & $62(3.52)$ & 1,689 & $61(3.61)$ \\
$6-10$ & 206 & $12(5.83)$ & 290 & $18(6.21)$ & 399 & $14(3.51)$ \\
$11-20$ & 85 & $12(14.12)$ & 146 & $12(8.22)$ & 283 & $13(4.59)$ \\
$>20$ & 59 & $14(23.73)$ & 176 & $28(15.91)$ & 395 & $49(12.41)$ \\
\hline
\end{tabular}

AKI, acute kidney injury; IOH, intraoperative hypotension; MAP, mean arterial pressure.

action between age and IOH. The results showed that the relationship between IOH and AKI after adjusting for age-related variables did not change, and variation in age was not statistically significant, after adjusting for confounders. The confounders were not statistically significant, suggesting that age did not interact with AKI and IOH in this sample.

\section{Discussion}

In this single-centre cohort study, we reported that postoperative AKI had a strong relationship with IOH in patients younger than 60 years old. Our findings were consistent with those reported in previous studies by Walsh et al. [9] (average age, approximately 55 years) 


\section{Kidney \\ Blood Pressure \\ Research}

Fig. 2. Predicted probability of acute kidney injury by lowest mean arterial pressure experienced during surgery.

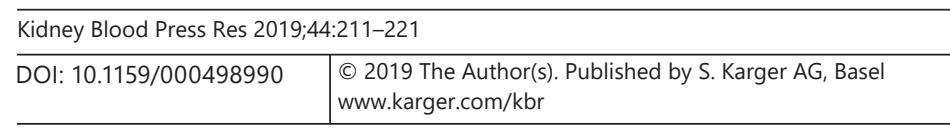

Tang et al.: Noncardiac Surgery-Related Acute Kidney Injury after Intraoperative Hypotension

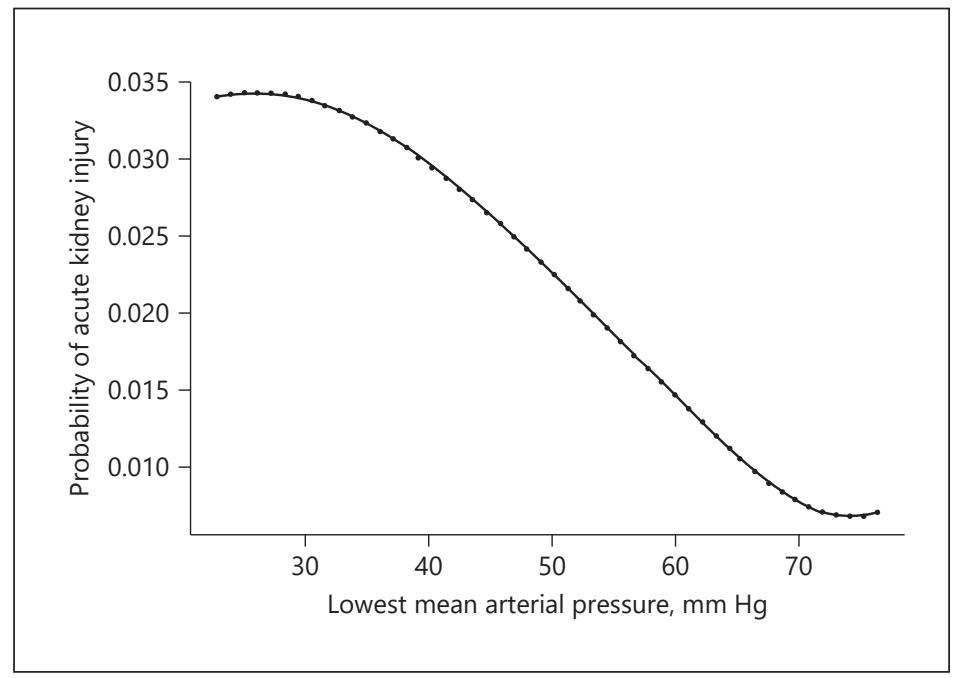

Table 3. Comparison of odds ratios of AKI across MAP "bands" (i.e., MAP <55, 55-59, and 60-64 mm Hg)

\begin{tabular}{|c|c|c|c|c|c|}
\hline \multirow{2}{*}{$\begin{array}{l}\text { MAP band, } \\
\text { mm Hg }\end{array}$} & \multicolumn{5}{|c|}{ Duration of intraoperative hypotension, min } \\
\hline & 0 & $1-5$ & $6-10$ & $11-20$ & $>20$ \\
\hline$<55$ & Ref. & $1.01(0.51-2)$ & $0.96(0.31-2.96)$ & $3.25(1.04-10.14)^{*}$ & $14.11(5.02-39.69)^{* * *}$ \\
\hline $55-59$ & Ref. & $0.75(0.35-1.62)$ & $1.14(0.37-3.51)$ & $2.40(0.85-6.75)$ & $7.46(3.14-17.72)^{* * *}$ \\
\hline $60-64$ & Ref. & $0.53(0.23-1.24)$ & $0.23(0.06-0.92)^{*}$ & $0.40(0.11-1.47)$ & $2.78(1.18-6.51)^{*}$ \\
\hline
\end{tabular}

${ }^{*} p<0.05,{ }^{* * *} p<0.001$. Adjusted for sex, age, haemoglobin, ASA grade, use of ACE inhibitors, $\beta$-blockers, $\alpha$-blockers, or diuretics, minimally invasive surgery, magnitude of surgery, emergency surgery, anaesthesia time, intraoperative erythrocyte transfusions, intraoperative haemorrhage, duration of surgery, hypertension, coronary heart disease, congestive heart failure, peripheral vascular disease, diabetes, and general anaesthesia.

and Sun et al. [10] (average age, approximately 62.9 years). In a retrospective cohort of 18,989 patients who underwent noncardiac procedures, Walsh et al. found a graded relationship between more than 5 min spent with a MAP of less than $55 \mathrm{~mm} \mathrm{Hg}$ or a MAP of $55 \mathrm{~mm} \mathrm{Hg}$ to $59 \mathrm{~mm} \mathrm{Hg}$ and stage I AKI. In an observational study of 5,127 patients, Sun et al. found that postoperative AKIN stage I AKI was associated with an intraoperative MAP of less than 55 $\mathrm{mm} \mathrm{Hg}$ for more than $10 \mathrm{~min}$ and a MAP of less than $60 \mathrm{~mm} \mathrm{Hg}$ for $11 \mathrm{~min}$ to $20 \mathrm{~min}$. Sun evaluated the patients' creatinine concentrations two days before surgery as the baseline for renal function, which was different from the common standard used by Walsh and recommended in the KDIGO guidelines. Linn Hallqvist et al. [14] found that an intraoperative reduction of SBP of more than $50 \%$ was associated with a greater than doubled risk of AKI and that the average age of patients was 67 years with no significant difference. In summary, the relationship between $\mathrm{IOH}$ and $\mathrm{AKI}$ in this study was much stronger than that reported in previous studies.

But as previous studies have suggested, patients younger than 60 years old might have better reserve renal function and thus be less likely to develop AKI than patients older than 60 years old with the same magnitude and duration of IOH. Reserve renal function decreases with ages [15], and the renal reserve of a normal 80-year-old person is less than half that of 


\section{Research}

Tang et al.: Noncardiac Surgery-Related Acute Kidney Injury after Intraoperative Hypotension

Table 4. Risk of AKI in patients experiencing different durations of intraoperative hypotension with MAP $<55 \mathrm{~mm} \mathrm{Hg}$

\begin{tabular}{llll}
\hline $\begin{array}{l}\text { Duration of IOH } \\
\text { MAP <55 mm Hg, min }\end{array}$ & AKI & \\
\cline { 2 - 4 } & model 1 & model 2 & model 3 \\
\hline 0 & Reference & Reference & Reference \\
$1-5$ & $1.86(1.33-2.58)^{* * *}$ & $1.04(0.53-2.04)$ & $1.01(0.51-2)$ \\
$6-10$ & $2.35(1.25-4.42)^{* *}$ & $1.05(0.35-3.15)$ & $0.96(0.31-2.96)$ \\
$11-20$ & $6.35(3.29-12.23)^{* * *}$ & $3.25(1.06-9.91)^{*}$ & $3.25(1.04-10.14)^{*}$ \\
$>20$ & $11.97(6.25-22.93)^{* * *}$ & $13.4(4.83-37.2)^{* * *}$ & $14.11(5.02-39.69)^{* * *}$ \\
\hline
\end{tabular}

${ }^{*} p<0.05,{ }^{* *} p<0.01,{ }^{* * *} p<0.001$. Model 1: adjusted for sex and age. Model 2: adjusted for sex, age, haemoglobin, ASA grade, use of ACE inhibitors, $\beta$-blockers, $\alpha$-blockers, diuretics, minimally invasive surgery, magnitude of surgery, emergency surgery, anaesthesia time, intraoperative erythrocyte transfusions, intraoperative haemorrhage, and duration of surgery. Model 3: adjusted for the same factors as model 2 and hypertension, coronary heart disease, congestive heart failure, peripheral vascular disease, diabetes, and general anaesthesia.

Table 5. Risk of different AKI stages (stages 1 to 3 by KDIGO) in patients experiencing different durations of intraoperative hypotension with MAP $<55 \mathrm{~mm} \mathrm{Hg}$

\begin{tabular}{llll}
\hline $\begin{array}{l}\text { Duration of IOH } \\
\text { MAP }<55 \mathrm{~mm} \mathrm{Hg}, \text { min }\end{array}$ & AKI & \\
\cline { 2 - 4 } & stage I & stage II & stage III \\
\hline 0 & Reference & Reference & Reference \\
$1-5$ & $1.18(0.34-4.08)$ & $0.96(0.33-2.84)$ & $0.9(0.27-3.05)$ \\
$6-10$ & $2.02(0.31-13.16)$ & $0.69(0.11-4.49)$ & $1.03(0.16-6.59)$ \\
$11-20$ & $10.92(1.94-61.52)^{* *}$ & $1.54(0.21-11.33)$ & $1.96(0.26-14.9)$ \\
$>20$ & $17.18(2.67-110.51)^{* *}$ & $11.28(2.24-56.85)^{* *}$ & $15.45(2.79-85.61)^{* *}$ \\
\hline
\end{tabular}

** $p<0.01$. All models adjusted for sex, age, haemoglobin, ASA grade, use of ACE inhibitors, $\beta$-blockers, $\alpha$-blockers, diuretics, minimally invasive surgery, magnitude of surgery, emergency surgery, anaesthesia time, intraoperative erythrocyte transfusions, intraoperative haemorrhage, duration of surgery, hypertension, coronary heart disease, congestive heart failure, peripheral vascular disease, diabetes, and general anaesthesia.

a 40-year-old person. Sumrani et al. [16] observed poor surgical outcomes after transplantation if kidneys were donated by a person who was older than 55 years of age. However, Walsh et al. did not exclude patients with pre-existing renal insufficiency. Sun evaluated the patients' creatinine concentrations two days before surgery as the baseline for renal function, which was different from the common standard used by Walsh and recommended in the KDIGO guidelines.

In addition, reserve renal function is challenged not only by hypertension [17] but also by diabetes [18]. Thus, although the patients included in our study were younger, their reserve renal function might have been different.

According to our analysis, patients younger than 60 years old seem to be more sensitive to IOH in terms of developing surgery-related AKI than those who were older than 60 years old. However, patients younger than 60 years old had a lower incidence of AKI and renal 
Tang et al.: Noncardiac Surgery-Related Acute Kidney Injury after Intraoperative Hypotension

Table 6. Interaction between age and the duration of intraoperative hypotension with $\mathrm{MAP}<55 \mathrm{~mm} \mathrm{Hg}$

\begin{tabular}{|c|c|c|c|c|c|c|c|}
\hline \multirow[t]{2}{*}{ Variable } & \multirow[t]{2}{*}{ Class } & \multicolumn{2}{|c|}{ Model 1} & \multicolumn{2}{|l|}{ Model 2} & \multicolumn{2}{|l|}{ Model 3} \\
\hline & & $\beta$ & $p$ value & $\beta$ & $p$ value & $\beta$ & $p$ value \\
\hline Intercept & & -3.678 & $<0.001$ & -3.155 & 0.342 & -3.024 & 0.493 \\
\hline \multirow[t]{4}{*}{ Time } & $1-5$ & 0.615 & $<0.001$ & 0.643 & $<0.001$ & 0.599 & 0.419 \\
\hline & $6-10$ & 0.895 & 0.005 & 0.909 & 0.005 & 0.231 & 0.871 \\
\hline & $11-20$ & 1.872 & $<0.001$ & 1.866 & $<0.001$ & 1.997 & 0.125 \\
\hline & $>20$ & 2.510 & $<0.001$ & 2.544 & $<0.001$ & 0.275 & 0.892 \\
\hline Age & & & & -0.012 & 0.108 & -0.015 & 0.180 \\
\hline \multirow{4}{*}{ Agextime } & $1-5$ & & & & & 0.001 & 0.945 \\
\hline & $6-10$ & & & & & 0.015 & 0.620 \\
\hline & $11-20$ & & & & & -0.003 & 0.917 \\
\hline & $>20$ & & & & & 0.049 & 0.251 \\
\hline
\end{tabular}

Model 1: no adjustment. Model 2: adjusted for age. Model 3: adjusted for age and age and time interaction terms.

replacement therapy (RRT) than who were those older than 60 years old. And in another observational study of 15,102 patients with normal preoperative renal function undergoing major noncardiac surgery, Kheterpal et al. [5] found that patients who had had more episodes of intraoperative MAP of less than $40 \mathrm{~mm} \mathrm{Hg}$ had a higher incidence of AKI (defined

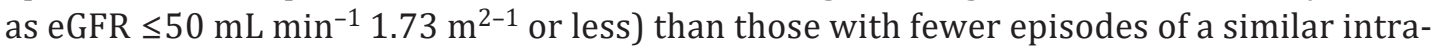
operative MAP, and age more than 56 years was identified a risk factor.

Our analyses have expanded on previous knowledge by demonstrating that age was neither an independent risk factor nor an interaction risk factor for developing AKI in patients younger than 60 years old undergoing noncardiac surgery. Even it has been suggested in a previous study [19] that eGFR and autoregulation of renal blood flow decrease with the ageing.

To our knowledge, renal perfusion is dependent on cardiac output. Patients undergoing cardiac surgery have a high incidence of AKI $[20,21]$ because extracorporeal circulation has countless negative effects, especially with a long duration of extracorporeal circulation. In addition, patients who have a poor cardiac output have an increased incidence of AKI incidences because the MAP may be decreased below the lower threshold of the autoregulation curve in these patients [22]. Although anaesthetic techniques, such as general anaesthesia or nongeneral anaesthesia, seem to be significant factors affecting the incidence of AKI, complex and different physiological conditions, as assessed by the ASA grade, allow assessment of patient risk. However, there are numerous anaesthesia techniques, which makes such an analysis complex.

This study used prospectively collected patient data from the Lex Clinical Data Application, which minimized the collection bias. With the number of patients, we were able to test age groups in different models with different IOH groups.

Our study also has some limitations. First, this was a retrospective observational study. Our study was limited by the available information within the database. Second, we excluded assumed artefacts based on pre-determined criteria. However, we were unable to determine the exact nature of these variations, which might be true reflections of the patient's condition. Third, our study could not address the direct link between AKI and IOH or other associated factors (e.g., low cardiac output, fluid and vasopressor administration, etc.). 


\section{Kidney \\ Blood Pressure Research}

\begin{tabular}{l|l}
\hline Kidney Blood Press Res 2019;44:211-221 \\
\hline DOI: 10.1159/000498990 & $\begin{array}{l}\text { @ 2019 The Author(s). Published by S. Karger AG, Basel } \\
\text { www.karger.com/kbr }\end{array}$ \\
\hline
\end{tabular}

Tang et al.: Noncardiac Surgery-Related Acute Kidney Injury after Intraoperative Hypotension

\section{Conclusion}

In conclusion, we found that patients younger than 60 years old had a fourteen-times increased odds of developing postoperative AKI after noncardiac surgery when they sustained $\mathrm{IOH}$ with a MAP of less than $55 \mathrm{~mm} \mathrm{Hg}$ for more than $20 \mathrm{~min}$. Cautious intraoperative BP management might be able to minimize this exposure among patients younger than 60 years old.

\section{Acknowledgements}

This work was supported by grants from the National Natural Science Foundation of China (No. 81371216 \& No. 81541028).

This work was supported by grant from the Hunan Science and Technology Innovation Program Project (No. 2018SK2094).

This study was also supported in part by the Research and Innovation Funds from Xiangya Bigdata Foundation of Central South University.

All authors are grateful to Mr. Lei Mo, Mr. Xuefeng Zhou and Ms. Ting Li from Le9 Health, Shanghai, China for their help in conducting the data extraction and data analysis for this study.

Yongzhong Tang, Bo Li for drafting and submission.

Chaonan Zhu, Min Yao for analysis the data.

Anli Wang, Hong Yuan for acquisition the data.

Wen Ouyang, Kaiming Duan for concept and design.

Jiabing Liu, Hao Zhang for revision.

\section{Disclosure Statement}

The authors declare that they have no competing interests.

\section{References}

1 Susantitaphong P, Cruz DN, Cerda J, Abulfaraj M, Alqahtani F, Koulouridis I, et al.; Acute Kidney Injury Advisory Group of the American Society of Nephrology. World incidence of AKI: a meta-analysis. Clin J Am Soc Nephrol. 2013 Sep;8(9):1482-93.

2 Zeng X, McMahon GM, Brunelli SM, Bates DW, Waikar SS. Incidence, outcomes, and comparisons across definitions of AKI in hospitalized individuals. Clin J Am Soc Nephrol. 2014 Jan;9(1):12-20.

3 Long TE, Helgason D, Helgadottir S, Palsson R, Gudbjartsson T, Sigurdsson GH, et al. Acute kidney injury after abdominal surgery: incidence, risk factors, and outcome. Anesth Analg. 2016 Jun;122(6):1912-20.

4 Rewa 0, Bagshaw SM. Acute kidney injury-epidemiology, outcomes and economics. Nat Rev Nephrol. 2014 Apr;10(4):193-207.

5 Kheterpal S, Tremper KK, Heung M, Rosenberg AL, Englesbe M, Shanks AM, et al. Development and validation of an acute kidney injury risk index for patients undergoing general surgery: results from a national data set. Anesthesiology. 2009 Mar;110(3):505-15.

6 Goudie ST, Deakin AH, Ahmad A, Maheshwari R, Picard F. Flexion contracture following primary total knee arthroplasty: risk factors and outcomes. Orthopedics. 2011 Dec;34(12):e855-9.

7 Coca SG, Peixoto AJ, Garg AX, Krumholz HM, Parikh CR. The prognostic importance of a small acute decrement in kidney function in hospitalized patients: a systematic review and meta-analysis. Am J Kidney Dis. 2007 Nov; 50(5):712-20.

8 Devereaux PJ; POISE-2 Investigators. Rationale and design of the PeriOperative ISchemic Evaluation-2 (POISE-2) trial: an international $2 \times 2$ factorial randomized controlled trial of acetyl-salicylic acid vs. placebo and clonidine vs. placebo in patients undergoing noncardiac surgery. Am Heart J. 2014 Jun;167(6):804-9.e4.

9 Walsh M, Devereaux PJ, Garg AX, Kurz A, Turan A, Rodseth RN, et al. Relationship between intraoperative mean arterial pressure and clinical outcomes after noncardiac surgery: toward an empirical definition of hypotension. Anesthesiology. 2013 Sep;119(3):507-15. 
10 Sun LY, Wijeysundera DN, Tait GA, Beattie WS. Association of intraoperative hypotension with acute kidney injury after elective noncardiac surgery. Anesthesiology. 2015 Sep;123(3):515-23.

11 Salmasi V, Maheshwari K, Yang D, Mascha EJ, Singh A, Sessler DI, et al. Relationship between Intraoperative Hypotension, Defined by Either Reduction from Baseline or Absolute Thresholds, and Acute Kidney and Myocardial Injury after Noncardiac Surgery: A Retrospective Cohort Analysis. Anesthesiology. 2017 Jan; 126(1):47-65.

12 Zhou J, Liu Y, Tang Y, Liu F, Zhang L, Zeng X, et al. A comparison of RIFLE, AKIN, KDIGO, and Cys-C criteria for the definition of acute kidney injury in critically ill patients. Int Urol Nephrol. 2016 Jan;48(1):125-32.

13 Doleman B, Blackwell J, Karangizi A, Butt W, Bhalla A, Lund JN, et al. Anaesthetists stress is induced by patient ASA grade and may impair non-technical skills during intubation. Acta Anaesthesiol Scand. 2016 Aug;60(7): 910-6.

14 Hallqvist L, Granath F, Huldt E, Bell M. Intraoperative hypotension is associated with acute kidney injury in noncardiac surgery: an observational study. Eur J Anaesthesiol. 2018 Apr;35(4):273-279.

15 Wijeysundera DN, Karkouti K, Dupuis JY, Rao V, Chan CT, Granton JT, et al. Derivation and validation of a simplified predictive index for renal replacement therapy after cardiac surgery. JAMA. 2007 Apr;297(16): 1801-9.

16 Sumrani N, Daskalakis P, Miles AM, Hong JH, Sommer BG. The influence of donor age on function of renal allografts from live related donors. Clin Nephrol. 1993 May;39(5):260-4.

17 Eriksen BO, Stefansson VT, Jenssen TG, Mathisen UD, Schei J, Solbu MD, et al. Blood pressure and age-related GFR decline in the general population. BMC Nephrol. 2017 Feb;18(1):77.

18 Turgutalp K, Bardak S, Horoz M, Helvacı I, Demir S, Kiykim AA. Clinical outcomes of acute kidney injury developing outside the hospital in elderly. Int Urol Nephrol. 2017 Jan;49(1):113-21.

19 Raman M, Middleton RJ, Kalra PA, Green D. Estimating renal function in old people: an in-depth review. Int Urol Nephrol. 2017 Nov;49(11):1979-88.

20 Xie X, Wan X, Ji X, Chen X, Liu J, Chen W, et al. Reassessment of Acute Kidney Injury after Cardiac Surgery: A Retrospective Study. Intern Med. 2017;56(3):275-82.

21 Jung SY, Park JT, Kwon YE, Kim HW, Ryu GW, Lee SA, et al. Preoperative Low Serum Bicarbonate Levels Predict Acute Kidney Injury After Cardiac Surgery. Medicine (Baltimore). 2016 Mar;95(13):e3216.

22 Rhee CJ, Kibler KK, Easley RB, Andropoulos DB, Czosnyka M, Smielewski P, et al. Renovascular reactivity measured by near-infrared spectroscopy. J Appl Physiol (1985). 2012 Jul;113(2):307-14. 